\title{
STUDY ON USE OF TYPHA ANGUSTIFOLIA L. IN WASTEWATER TREATMENT: PROMISING METHOD IN REMOVAL OF COPPER IONS PRESENT IN AQUATIC SOLUTION
}

\author{
Andreea Catalina Cristescu ${ }^{1}$, Cristina Covaliu ${ }^{2}$, Lucretia Popa ${ }^{1}$, Daniel Dumitru ${ }^{1}$, Alexandra Anghelet ${ }^{1}$ \\ ${ }^{1}$ National Institute of Research-Development for Machines and Installations Designed to Agriculture \\ and Food Industry, Romania; ${ }^{2}$ University Politehnica of Bucharest, Romania \\ andreea.catalina.cristescu@gmail.com, cristina_covaliu@yahoo.com, lucretia_popa@yahoo.com, \\ dumitrudanielmarian@yahoo.com, anghelet.alexandra@yahoo.com
}

\begin{abstract}
Water pollution is an increasingly troublesome problem, water being a precious, renewable, but limited resource, and an essential factor in maintaining life on the earth. With the increasing population number, the strong and uncontrolled industrialization, and the aggressive behaviour of the population, relative to environmental protection, more and more toxic residues and substances have been released into the environment, jeopardizing its balance. The treatment of water contaminated with heavy metal ions is a real challenge, due to the fact that the costs of applying the current treatment technologies are very high, with low efficiency. Due to the high toxicity of heavy metals, the serious effects they have on the abiotic factor, but also the toxic effects and illnesses they cause to living organisms, researchers have focused their attention on the implementation of new effective solutions in order to eliminate these toxic pollutants. This paper aims to highlight a less conventional method used for treating water contaminated with heavy metal ions. The process is based on the ability of the Typha angustifolia L. to metabolize the heavy metal ions present in the water, and it also has the advantage of recovering the metal from the plant, at the end of its growth process. The paper wanted to highlight an efficient method, which implementation and functioning does not harm the environment. Taking into account the promising results of the experiments and the low costs involved in using this method of treating wastewater contaminated with heavy metal, it is desirable to implement it or to use it on a large scale. Studies will also be continued within a research project from the National Research Plan, in order to observe the plant's effectiveness in adsorbing other types of heavy metals.
\end{abstract}

Keywords: wastewater, phytoremediation, bioaccumulation, copper, biosorption.

\section{Introduction}

Heavy metals are considered extremely toxic and must be removed from water. The main methods for removing heavy metals from water are precipitation and ion exchange. These methods are not very effective mostly because the cost of using them is significant. As an alternative to these methods, bioremediation is used as a method that can provide a high efficiency at a low-cost.

Bioremediation is considered to be the process, by which living organisms (micro-organisms, plants, etc.) are used to restore different anthropic environments to the original state, free from toxic pollutants. Bioremediation is a modern method based on the ability of certain organisms to turn pollutants into less dangerous or, ideally, non-hazardous factors, without making substantial changes in the equilibrium of the ecosystem. It is based on the ability of some chemicals to be biodegraded [1].

Bio-treatment has applications in domestic wastewater treatment, industrial wastewater treatment, etc. The term mainly involves the following definitions:

- use of living organisms to degrade environmental pollutants to prevent pollution or waste treatment;

- application of biological treatments for cleaning, decontamination and degradation of hazardous substances.

Biosorption is the ability of certain biomolecules or biomass to adsorb certain ions or other molecules from aqueous solutions. This process is a very efficient one, bringing water polluted with heavy metals with a concentration of $1-100 \mathrm{mg} \cdot \mathrm{l}^{-1}$ to the quality of drinking water with a contraction of heavy metal ions of $0.01-0.1 \mathrm{mg} \cdot \mathrm{l}^{-1}[1]$.

Bioaccumulation is the process that is based on active metabolic transport of living organisms and the metabolism of certain heavy metal substances and ions [2].

Recently, various biosorbent materials have been introduced into the wastewater treatment technology. Such materials are a good alternative to the conventional methods that are currently used. 


\section{Bioremediation of wastewater loaded with heavy metal ions}

Phytoremediation is a bioremediation branch, consisting of a set of technologies that use plants to treat contaminated water, based on the ability of plants to bioaccumulate various substances. Macrophytes have great properties in accumulation of heavy metals, with high bioaccumulation capacities. A few examples of plants with such proprieties are: water plague (Elodea canadensis), water mint (Mentha squatica), strawberry salad (Pistia stratiotes), water scent (Eichornia crassipes) (Vallisneria spiralis), reed (Phragmites communis, Salvinia, spirodella, Lemna, ceratophyllum demersum), papura (Typha sp., T. latifolia, T. angustifolia), rouge (Scirpus sp. Glyceria maxima), white grass (Phalaris arundinacea). Phytoremediation is a very advantageous method, because it can be applied for both organic and inorganic substances [3].

The purification process takes place in the filter bed and consists in decomposition of organic matter, phosphorus retention, nitrification of nitric compounds, the role of plants is to extract, degrade or immobilize harmful substances in water.

Phytoremediation is defined as the process of using plant species to remove various toxic compounds from environments such as water, soil and air. In principle, it is based on the use of natural plants or genetically modified plants [4].

The primary reason why this method has been used is to collect certain substances, such as heavy metals, and to make them easy to extract. Through various biophysical and biochemical processes, such as adsorption, transport and translocation, hyperaccumulation or transformation and mineralization, plants can remedy various pollutants [1-3].

\section{Phytoremediation mechanisms}

The mechanism and efficiency of the pond treatment depends on the content, bioavailability and water properties. There are various ways in which plants can adsorb heavy metals, mainly the most important part of the plant that has applicability in this process, is the root. The root of the plant adsorbs the nutraceuticals needed to grow the plant, along with other compounds that will be translocated to the upper part of the plant where they will be accumulated. Plants used in wastewater treatment have a high tolerance to heavy metals. After the plant development process has been completed, they will be removed and heavy metals can be recovered [2].

Phytofiltration is the use of both terrestrial and aquatic plants to adsorb, concentrate and precipitate toxic metals from various aquatic environments. This method can be used to treat water loaded with lead, copper, chromium, cadmium, nickel, zinc ions, which are initially retained in the plant root. The ideal feature of these plants is the ability of the root to grow very quickly and adsorb heavy metals in as short a time as possible. After the metal saturation of plants, which forms precipitations on the root of the plant, the whole plant or only the root is harvested. This precipitation is due to the fact that the root exudates and $\mathrm{pH}$ changes in the rhizosphere. Sunflower, tobacco and Indian mustard were used as an experiment, where sunflower had the best results. The advantage of this method is the possibility of using both aquatic and terrestrial plants for both methods: in situ and ex situ. It is preferable to use terrestrial plants because they have a fibrous strain, a much more developed root, with a much higher adsorption space [4].

Phytoremediation applications are:

- phytoextraction - technology that extracts pollutants from the plant root system and translocate them into plants biomass, which can later be used as the essential nutrient;

- risofiltration - adsorption or precipitation on plant roots or absorption of pollutants from the solution around the roots;

- phytostabilization - immobilisation of pollutants into the soil by absorption on the root system or by precipitation inside the root zone of the plants;

- phytodegradation (phyto transformation) - elimination of accumulated pollutants, through metabolic processes or processes produced by enzymes

- risodegradation - destruction of organic polluting substances through microbiological activities carried out in the plant root zone [5]. 
Other advantages:

- the cost of phytoremediation is lower than for traditional processes;

- reduced environmental impact;

- plants can be easily monitored - the possibility of recovering and reusing precious metals.

A major drawback of phytoremediation is that it requires a long-term commitment, because the process is dependent on the plant growth, tolerance to toxicity and bioaccumulation capacity.

Phytoremediation may be limited by:

- depth of the treatment area depends on the type of the plant used in pond treatment;

- high concentrations of hazardous substances may be toxic to plants;

- sometimes it can only be done in certain seasons;

- pollutants can be transferred between environments;

- toxicity and bioavailability of degradation products are not always known;

- products can be transferred to groundwater or bioaccumulated in animals [1].

\section{Materials and methods}

In order to carry out the experiment the following laboratory equipment and reagents were used:

- analytical balance with a precision of 5 decimal;

- balloon lab bottles;

- Erlenmayer glasses of $5 \mathrm{ml}, 500 \mathrm{ml}$;

- watch glass;

- pipette;

- spatula;

- bidistilled water;

- copper chloride $\left(\mathrm{CuCl}_{2} \times 2 \mathrm{H}_{2} \mathrm{O}\right)$;

- UV-Vis spectrophotometer SPECORD 200 PLUS.

\section{Calibration curve}

A mass of $0.0317 \mathrm{~g} \cdot \mathrm{ml}^{-1}$ of $\mathrm{CuCl} 2$ (where copper has 63.546 atomic mass and the atomic mass of chlorine is 35.453) was weighted and added in an Erlenmayer glass with distillate water, representing the stock solution. From this stock solution samples were made as follows: in the first glass $1 \mathrm{ml}$ was poured, in the second $3 \mathrm{ml}$, and in the third $4 \mathrm{ml}$, and mixed with bidistilled water. It results that the first glass has a mass of $0.00634 \mathrm{~g} \mathrm{Cu}$, the second $0.01902 \mathrm{~g} \mathrm{Cu}$ and the third $0.02536 \mathrm{~g} \mathrm{Cu}$. The water used is synthetic wastewater containing bidistilled water, in which $\mathrm{CuCl} 2$ is dissolved. In the samples the roots of Typha angustifolia were introduced, with dimensions of: $21 \times 2.5 \times 3$ and $16.5 \times 1.5 \times 2$.

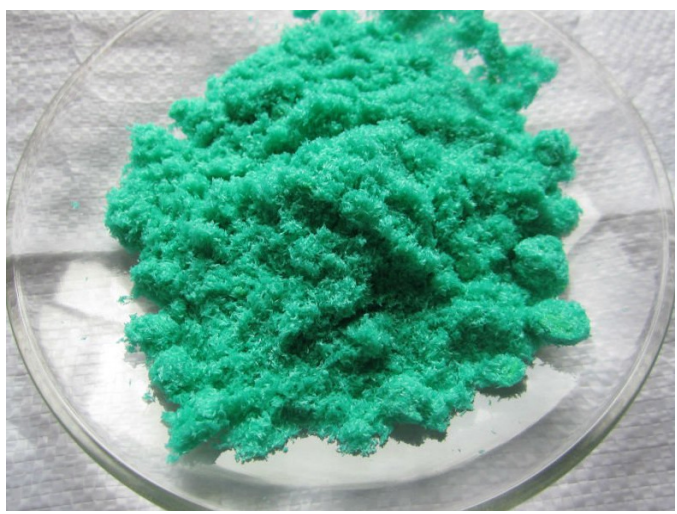

Fig. 1. Copper chloride

In the next step, the spectrophotometric method was used in order to observe the copper chloride calibration curve. Table 1 shows the concentration and absorbance read on the spectrophotometer. In Fig. 2, the calibration curve and the equation used in order to calculate the concentration are presented. 


\section{Concentration and absorbance read on spectrophotometer}

Table 1

\begin{tabular}{|c|c|}
\hline Concentration, $\mathbf{g} \cdot \mathbf{I}^{\mathbf{1}}$ & Absorbance, a.u. \\
\hline 0.00634 & 0.4778 \\
\hline 0.01902 & 1.0458 \\
\hline 0.02536 & 1.2645 \\
\hline 0.0317 & 1.4669 \\
\hline
\end{tabular}

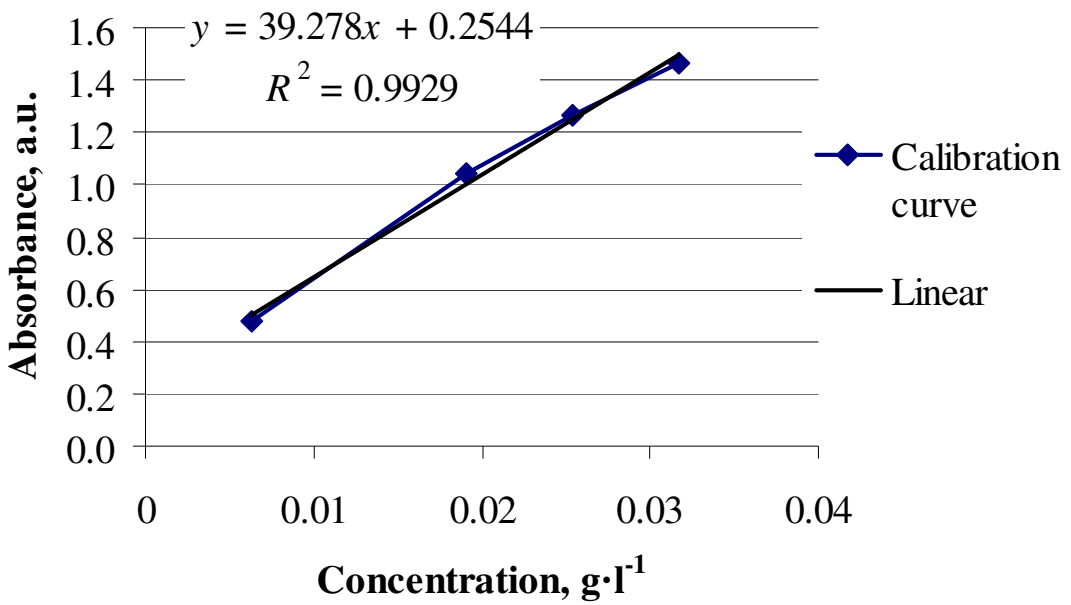

Fig. 2. Calibration curve

In order to determinate the efficiency of Typha angustifolia L., from the absorbance equation we will find the concentration of the water treated with rust and then the yield.

The absorbance equation is:

$$
\begin{gathered}
A=a \cdot x-b, \\
A=0.0253 \cdot C-0.0063,
\end{gathered}
$$

where $A$-adsorbance;

$C$ - concentration.

The yield of the reaction is calculated with the following formula:

$$
\eta=\frac{c_{i}-c_{f i}}{c_{i}} \cdot 100,
$$

where $\eta$-yield of the reaction;

$c_{i}$ - initial concentration;

$c_{f i}-$ final concentration over time.

The initial concentration is:

$$
\begin{gathered}
c_{i}=(0.02982 \cdot 63.55) / 147.02 \mathrm{~g} \cdot \mathrm{ml}^{-1}, \\
c_{i}=0.0128 \mathrm{~g} \cdot 500 \mathrm{ml}^{-1}, \\
c_{i}=0.0257 \mathrm{~g} \cdot \mathrm{l}^{-1},
\end{gathered}
$$

where $0.02982-\mathrm{CuCl}_{2}$ mass weighed for $500 \mathrm{ml}$;

147.02 - weighted copper mass;

63.55 - molar mass. 


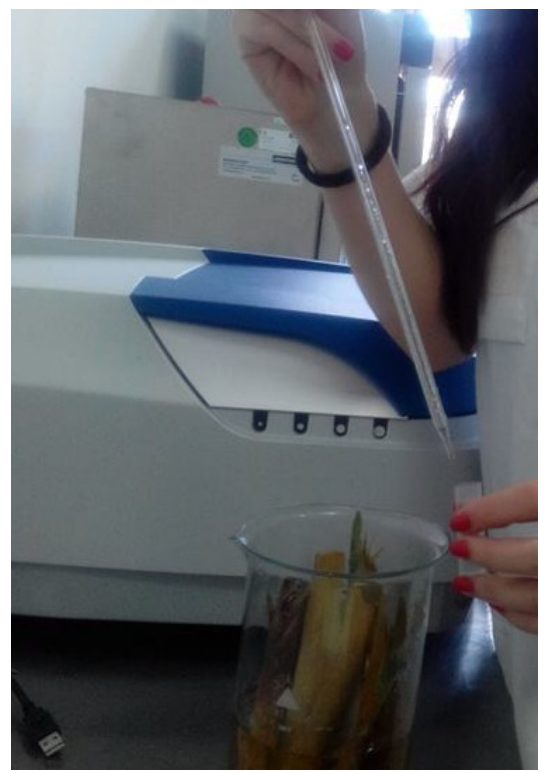

Fig. 3. Sampling

\section{Results and discussion}

After a while, the samples of the water treated with Typha angustifolia $\mathrm{L}$. were taken to measure the absorbance and calculate the efficiency of the process, which is presented in Table 2 and Fig 1, 2.

Table 2

\section{Results during the experiment}

\begin{tabular}{|c|c|c|c|}
\hline Time, min & Concentration, $\mathbf{g} \cdot \mathbf{I}^{\mathbf{1}}$ & Adsorbance, a.u & $\boldsymbol{\eta}, \boldsymbol{\%}$ \\
\hline 0 & 0.01656 & 0.4102 & 35.56 \\
\hline 39 & 0.01468 & 0.3652 & 42.87 \\
\hline 7082 & 0.01053 & 0.2603 & 58.91 \\
\hline 7114 & 0.00935 & 0.2303 & 63.61 \\
\hline 7128 & 0.00895 & 0.2202 & 65.17 \\
\hline 7148 & 0.00787 & 0.1929 & 69.37 \\
\hline 7164 & 0.00569 & 0.1379 & 77.85 \\
\hline
\end{tabular}

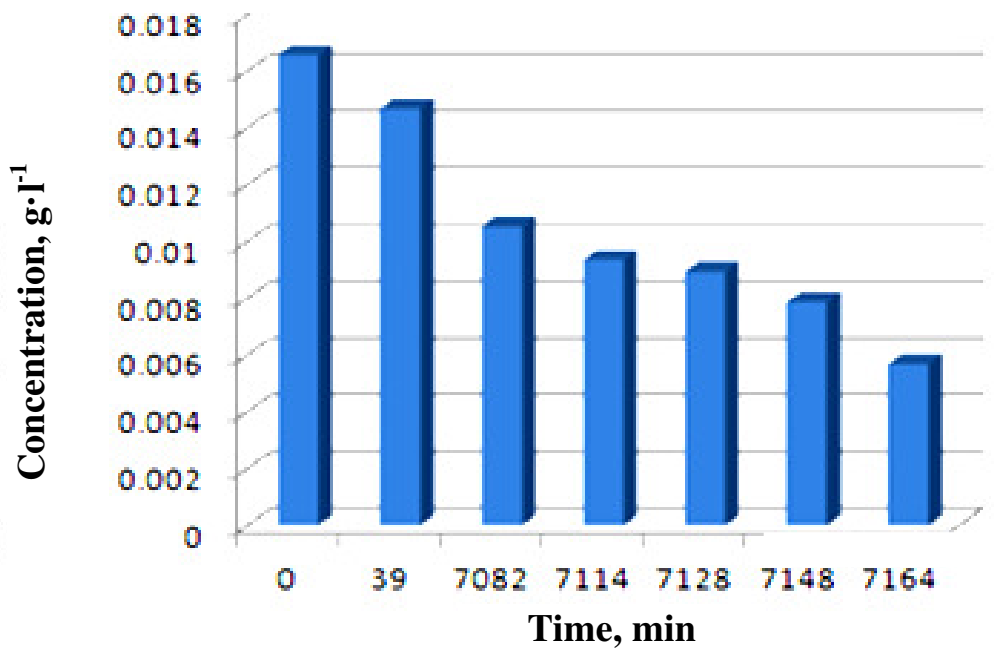

Fig. 3. Copper oncentration by time 


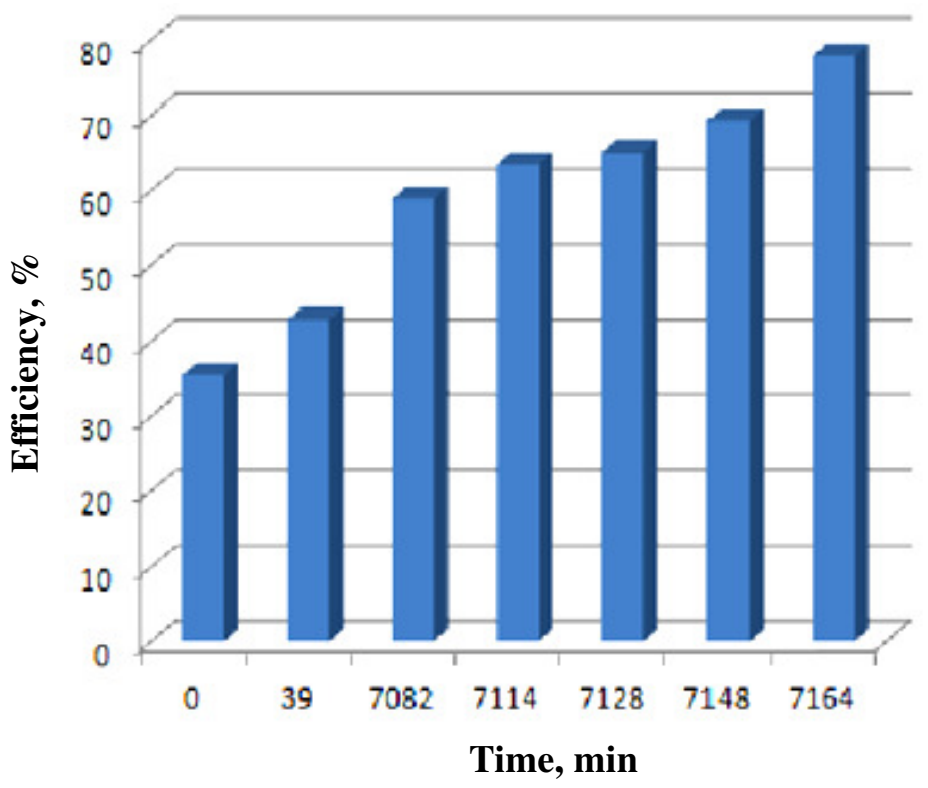

Fig. 3. Effectiveness of Typha angustifolia $\mathbf{L}$. to remove copper from the aqueous solution according to time

\section{Conclusions}

Purification of heavy metals in wastewater is a delicate research problem. With awareness of the devastating effects of heavy metal pollution on humans and the environment, various steps have been taken to determine a more effective solution to halting this phenomenon and diminishing the environmental impact they have.

Researches in the field of industrial water treatment are in continuous development and aim to find the optimal solution for water treatment. For now, the most used methods for treating heavy metal ions are:

- ion exchange

- filtering (NF, MF, UF, OI)

- adsorption

- precipitation

- electrolysis

- flotation

- bioremediation, etc.

The present experiment has shown the efficiency of Typha Angustifolia L. in wastewater treatment. In five days, it has shown the efficiency of $77.85 \%$, which encourages the research in this subject. In the economical aspect, this is a very cheap method, which can imply a tank, where the plants can be grown in order to treat the polluted water that can be pumped. The disadvantage of this method is represented by the fact that the water treatment is directly proportional to the process of the plant growth. The experiment follows the idea of implementing an ecological and economical method of wastewater treatment, where no other chemicals will be used.

Based on the results of the experiments, it can encourage for further more researches in this field, aiming to promote the idea of ecological wastewater treatment worldwide.

The technology presented in the present paper has a great potential in becoming the basis of the principle of sustainable development in this field, which promotes activities that do not affect the environment.

Recovery processes by phytoremediation of the heavy metal ion loaded water, presented in the present paper, provide the advantage of carrying out the purification together with the recovery of the 
metals present in the purified water and encourages further researches in order to apply this method on a large scale.

\section{Acknowledgement}

This work was supported by a grant of the Romanian National Authority for Scientific Research and Innovation, CNCS/CCCDI - UEFISCDI, project number PN-III-P2-2.1-PTE-2016-0183 (25/2016 "Improved flotation treatment technology for heavily loaded wastewaters"), within PNCDI III."

\section{References}

[1] Araújo C. S. T., Carvalho D. C., Rezende H. C., Almeida I. L. S., Coelho L. M., Coelho N. M. Marques T.L., Alves V. N. "Bioremediation of Waters Contaminated with Heavy Metals Using Moringa oleifera Seeds as Biosorbent", Applied Bioremediation - Active and Passive Approaches, 2013.

[2] Popa și R. G., Badea D. N. "Study on the use of fertilizer plants in water conservation in gorj county, within the durabiled development", Analele Universităţii "Constantin Brâncuşi”" Târgu Jiu, Engineers Series, nr. 2, , 2011, pp. 130-139.

[3] Archana S. H., Jaitly A.K. "Bioremediation: Environmental Biotechnology for heavy metals decontamination of soil \& water," Biochem. Cell Arch., nr. 14, pp. 259-281, 2014.

[4] Sardrood B. P. “An Introduction to Bioremediation,” Springer-Verlag Berlin, 2013.

[5] Mosoarca G., Vancea C., Popa și S., Boran S. "Adsorption, Bioaccumulation and Kinetics Parameters of the Phytoremediation of Cobalt from Wastewater Using Elodea canadensis," Bulletin of Environmental Contamination and Toxicology, 2018. 